\title{
Return and Volatility Spillover between Financial Market Participants of Dhaka Stock Exchange Using Asymmetric GARCH Methods
}

\author{
Mohammad Kamrul Arefin and Sharif N. Ahkam
}

\begin{abstract}
This paper is an investigation of the comovement in the form of return and volatility spillover across financial market participants of Bangladesh. This study uses daily price data of commercial banks, non-bank financial institutions (NBFI), and insurance companies traded in the Dhaka Stock Exchange (DSE) for the period spanning 2009 to 2016. Bayesian Vector Autoregressive (VAR) model has been used in the conditional mean equations of EGARCH and GJR-GARCH models have been used to test the return spillover effects whereas lagged squared residuals and lagged conditional variances have been used as variance regressors in conditional variance equations to test the spillover effects of historical volatility and innovations transmitting in the form of shock to other participants operating in the same market. Bayesian VAR output reveals a highly significant bi-directional return spillover between bank-insurance pair and also between NBFIs-insurance pair. However, return spillover between commercial banks and NBFIs is unidirectional; only bank returns are affecting returns from NBFIs. Conditional volatility of NBFIs exhibit a highly significant asymmetric effect implying that bad news increases volatility of NBFIs to a greater degree than good news. Both GJR-GARCH and EGARCH output reveal bidirectional volatility spillover in the form of historical volatility and innovations among commercial banks, NBFIs and insurance companies.
\end{abstract}

Index Terms-Bayesian VAR, E-GARCH, GJR-GARCH, return spillover, volatility spillover, DSE.

\section{INTRODUCTION}

Stock market is like a thermometer of an economy that can measure the temperature and can provide an image of a country's economic health. Since its inception, Bangladesh stock market has undergone several restructuring after experiencing severe turmoil including the stock market collapse in 1996 and in 2011 where some major players created bubble or an abnormal hike in price through syndicated trading. The bubble eventually burst when it became clear that the abnormally high level of prices are not supported by market fundamentals. As a consequence, investors lost their trust in the market, a widespread panic set

Manuscript received January 19, 2017; revised March 20, 2017.

M. K. Arefin is with Eastern University, Dhaka, Bangladesh (e-mail: arefin.fba@easternuni.edu.bd).

S. N. Ahkam is with North South University, Dhaka, Bangladesh (e-mail: sharif.ahkam@northsouth.edu). in causing a market crash and created unusually large downward spike in the volatility graph.

Although volatility is attributed as risk, it is a very vital ingredient for a healthy stock market and is important to encourage speculators to contribute to the liquidity in the market. The volatility graph of a healthy stock market is akin to an echocardiogram report of a healthy individual with no abnormal spike and no abnormal fall in there.

Globalization, free flow of capital and technological advances have given rise to highly integrated financial markets and have increased co-movement in stock prices across local and international markets. Theoretically, stock market encourages accumulation of capital and acts as a channel for efficient capital allocation. Hence, a country's stable stock market indicates stability of the economy and thus will attract investors to the country. With rapid transmission of news, disturbances in one stock can impact returns and/or volatilities of other participants in the same market and can eventually be transmitted to local and international markets. Asset pricing model states that the return of an asset depends on its own return variance or to the covariance between its return and the return on the market portfolio [1], [2]. Thus, for effective portfolio allocation and hedging decisions, analyzing the comovement dynamics between stock market participants can be a very powerful tool.

Volatility spillover or financial shock transmission across commodities and markets of developed economies have been studied quite extensively. However, with the increased integration and comovement among the developed economies, the potential for diversification benefit is disappearing for international investors. These investors started moving to emerging economies in search of diversification benefits Bangladesh stock market appears to be less integrated with others as it was relatively less affected by global recession in recent past. These poor integration provides enormous diversification benefits for international investors. In this study we would like to investigate comovement in the form of return and volatility spillover among financial market participants such as commercial bank sector, NBFIs, and insurance industry.

The section one of this study is the introductory part. The rest of the study is structured in six sections. The second section of the study will present an overview of related literature; section three is about preliminary data analysis. The section four provides a brief on empirical models used in this paper and continued in section five where all empirical findings have been presented. Finally, the conclusion and 
summarization of the findings are presented in section six.

\section{LITERATURE REVIEW}

Interrelationship and dynamic linkage among stock market participants inside and outside an economy have generated strong interest among researchers and policy makers, especially after the Asian crisis (1997-98) and US subprime mortgage crisis. The world has witnessed major financial crises occurring in the US and European economies and the repercussions were felt all over the world and eventually in the emerging markets. Dhaka Stock Exchange attracted global investors as it was the least affected market among the markets in emerging economies during previous global financial crises.

Diversification benefit increases with the decrease in correlation and comovement between stock market participants in a market and between markets. International investors must regularly examine the extent of integration of financial markets in the form of return and volatility spillover to manage portfolio risk. As for Dhaka Stock Exchange, the authors could locate only a handful of articles focusing on the volatility of Dhaka Stock Exchange. However, no research work on return and volatility spillover across industries of Bangladesh stock market was found.

Rayhan et al. [3] examined generalized autoregressive conditional heteroskedasticity $(\mathrm{GARCH})$ properties in the monthly DSE returns series. Other researchers, such as, [4] and [5] used GARCH framework to identify the best model to forecast volatility in Dhaka Stock Exchange. Mollik and Bepari [6] used autocorrelation structure and GARCH framework in the return series of DSE general and DSE 20 index and didn't find any asymmetric or differential impact of bad news and good news on the conditional variance of DSE return series. However they observed significant effect of historical volatility on DSE return series in the form of highly significant autocorrelation. Miah and Rahman [7] used different GARCH specifications to predict volatility of DSE stock returns and observed significant $\mathrm{ARCH}$ presence in the form of volatility clustering and they concluded that GARCH $(1,1)$ is the best model in predicting volatility of DSE stock returns. Basher et al. [8] observed a statistically significant negative relationship between conditional volatility and stock returns and attributed circuit breaker as a causal factor that contributed significantly to the volatility of realized returns. Rahman et al. [9] examined a wide variety of GARCH models under different distributional assumptions, but models under student- $\mathrm{t}$ distributional assumptions were found to be suitable for modelling volatility of Chittagong Stock Exchange.

The strong research interest on examining market integration, and more specifically, volatility spillovers has led to the development of several models based on GARCH/ARCH and their respective extensions. A major advance in measuring volatility spillover has been allowing the current variance to depend on its own previous lags which enabled the model to include all necessary information into a much simpler and more parsimonious equation. This has enabled the ARCH and GARCH models to provide a reliable volatility measure since both the market trend and its corresponding volatility pattern are simultaneously accounted for over time [10]. However, among the available family of models, the jury is still out to sort out which model performs better in forecasting volatility.

One major issue with the GARCH models is the inbuilt symmetric response to positive and negative volatility shocks. Squaring of the lagged residuals in the conditional variance equation loses the sign and along with the loss, the separation of positive and negative shocks is lost. Since a negative shock is likely to increase the level of volatility more than a positive shock of the same magnitude, a symmetric GARCH may not account for potential leverage effects [11]. This limitation has led to the development of further extensions of the GARCH model. Nelson's [12] E-GARCH and Glosten, Jagannathan and Runkle's [13] GJR-GARCH are two popular extensions of the univariate GARCH model that address potential asymmetries.

Empirical results vary on which of these models provides the best volatility forecasts. According to research done by Liu and Hung [14], GJR-GARCH achieves the better volatility forecasts with E-GARCH just slightly behind. On the contrary, Mukherjee and Mishra [15] found that E-GARCH was a better model compared to the T-GARCH (also referred to as GJR-GARCH) model for the SENSEX perhaps because there was considerable amount of asymmetry in the series. Kanas [16] used an E-GARCH model to evaluate the volatility spillover between the European stock markets of London, Frankfurt and Paris.

Koutmos and Booth [17], Braun $f$ [18], and Kroner and $\mathrm{Ng}$ [19] propose an extension to Nelson's model by providing a bivariate E-GARCH model to study asymmetry in volatility transmission mechanism. This extension to the E-GARCH model had been applied to study volatility transmission in the context of the Asian financial crisis and the 2007-09 subprime mortgage crisis (see, for example, [20], [21] and [22] among many others). Liu and Hung [14] point out that a GARCH model with normal distribution is more desirable than the more sophisticated error distribution models when asymmetries are ignored. However, they also emphasize that modelling asymmetric components is more important than specifying error distribution.

In this paper, Bayesian vector auto-regressive (VAR) model in the conditional mean equation of asymmetric E-GARCH and GJR-GARCH model have been used to predict return and volatility spillover between commercial banks, non-bank financial institutions and insurance companies of Dhaka Stock Exchange.

\section{DATA}

In order to analyze the diffusion of volatility or volatility spillover effects between financial market participants, we have collected daily price data of commercial banks, NBFIs and insurance companies traded in Dhaka Stock Exchange (DSE) from January, 2009 to January, 2016. Index prices have been calculated for commercial banks, NBFIs and insurance companies by taking the daily price of the selected stocks in the group and averaging them. The average prices have been converted into continuously compounded rate of 
return $\left(R_{t}\right)$ by taking the first difference of the log prices, i.e.,

$$
R_{t}=\ln \left(p_{t} / p_{t-1}\right)
$$

Initially we perform descriptive statistics analysis on the price and return series of the data. The normality test on the data has been carried out by calculating skewness, kurtosis and Jarque-Bera coefficient. Table I provides wide range of descriptive statistics for all return series. All return series exhibit loss with a very small mean (less than $0.5 \%$ ). The frequency of negative returns for commercial banks for the 2009 to 2016 time series period has been found higher compared to insurance and NBFIs.

The standard deviations of returns are much greater than the means in absolute value, indicating that the means are not significantly different from zero. This is consistent with common knowledge that financial time series at this frequency usually follow a random walk. Commercial bank returns exhibit the highest volatility $(4.52 \%)$, followed by NBFIs (3.98\%) and insurance companies (3.22\%). Skewness and kurtosis values indicate that the distributions of returns for all return series are negatively skewed and leptokurtic. These findings indicate that the distributions of all return series are typically asymmetric, and that the probability of observing large negative returns is higher than that of a normal distribution. Not surprisingly, the Jarque-Bera test statistics (JB) clearly confirm the rejection of the null hypothesis of normality for all return series. The Ljung-Box q-statistic at lag 12 and lag 24 is calculated for all return series to test whether the series are white noise or if there is any autocorrelation up to lag of order 12 and 24 and from the output we reject the null hypothesis that there is no autocorrelation up to lag 12 and lag 24 for all return series except for banking series at lag 24.

TABLE I: DESCRIPTIVE STATISTICS

\begin{tabular}{lccc}
\hline Return series & $\begin{array}{c}\text { Commercial } \\
\text { Bank (x) }\end{array}$ & NBFI (y) & Insurance (z) \\
\hline Mean & -0.002106 & -0.001789 & -0.001958 \\
Median & -0.001532 & -0.001003 & -0.001208 \\
Maximum & 0.128381 & 0.183701 & 0.094898 \\
Minimum & -1.678044 & -1.103816 & -1.029831 \\
Std. Dev. & 0.045239 & 0.039801 & 0.032222 \\
Skewness & -30.11391 & -16.16837 & -19.74151 \\
Kurtosis & 1114.954 & 409.1059 & 616.6291 \\
Jarque-Bera & $87424898 * * *$ & $11700719 * * *$ & $26656022 * * *$ \\
Lb-q(12) & $28.659 * * *$ & $37.955 * * *$ & $185.62 * * *$ \\
Lb-q(24) & 31.042 & $42.842 * * *$ & $192.68 * * *$ \\
Observations & 1692 & 1692 & 1692 \\
\hline
\end{tabular}

*** implies significance at $1 \%$ level.

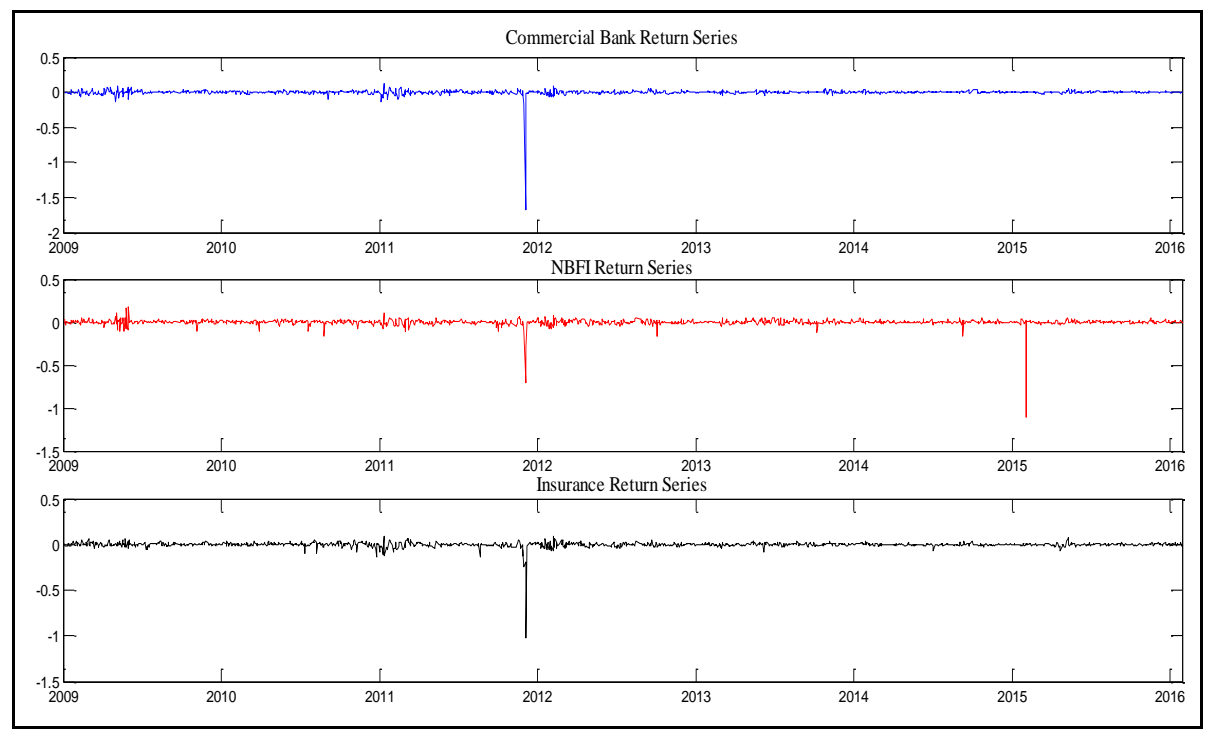

Fig. 1. Daily return series of commercial banks, NBFIs and insurance companies.

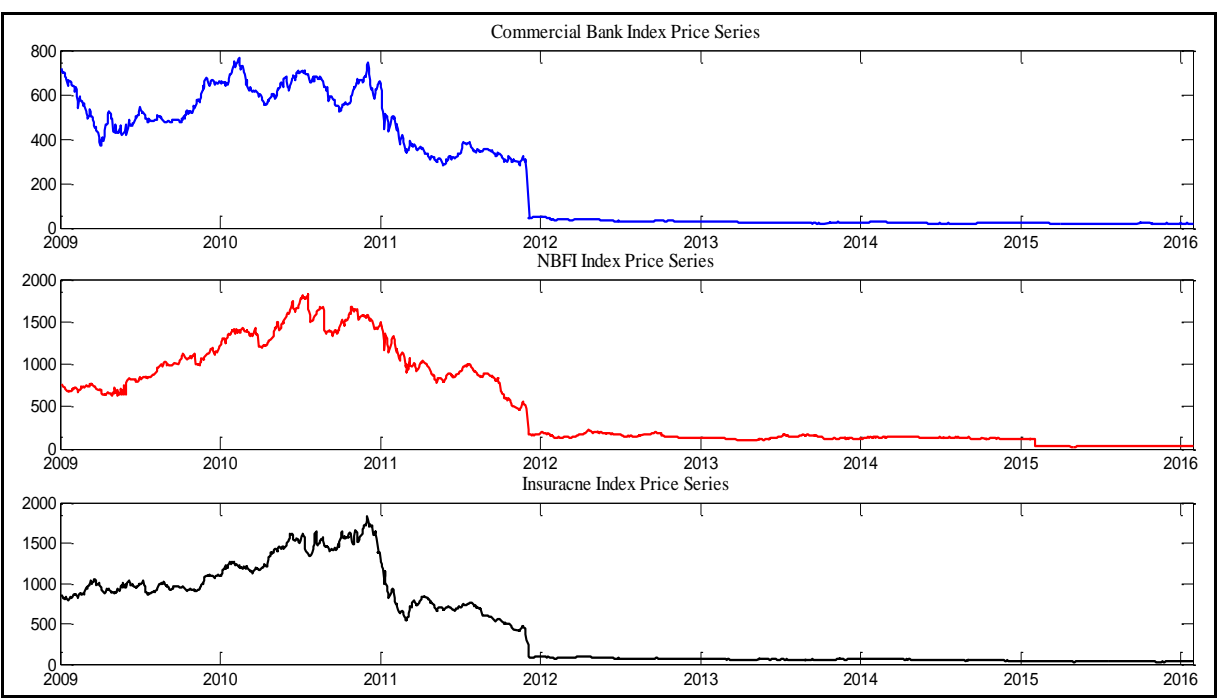

Fig. 2. Daily price series of commercial banks, NBFIs and insurance companies. 
As mentioned in Yang et al. [23], the correlation of market returns of different stocks can be interpreted as an indicator of the comovement between these stocks. Thus, a higher positive correlation means a higher level of comovement between the stocks which implies that it is more difficult to diversify portfolio risk by investing in these different stocks. Based on the unconditional correlations in Table II, we can say that all return series are positively related to one another indicating that all the stocks have been moving in the same direction (up or down) during the sample period. Pairwise Granger causality test, presented in Table III, has been performed to get a preliminary idea about the comovement dynamics and a highly significant causal effect has been observed between all return series except that NBFIs have no effect on commercial banks. The Augmented Dickey Fuller (ADF) test and Phillips-Perron test of unit roots, presented in Table IV, are used to test stationarity of the variables to ensure that outcome of the analysis is not spurious [24], [25]. All return series are stationary indicating that it is possible to predict a long run relationship between the variables. The graphical representation in Fig. 1 and Fig. 2 in the appendix indicates that the return series exhibits volatility clustering as periods of low volatility mingled with periods of high volatility. This is a clear sign of presence of ARCH effect in the series.

\begin{tabular}{lccc}
\multicolumn{4}{c}{ TABLE II: CORRELATION MATRIX } \\
\hline & $\begin{array}{c}\text { Commercial } \\
\text { Banks (x) }\end{array}$ & NBFI (y) & Insurance (z) \\
\hline Commercial & 1.000000 & 0.463418 & 0.240646 \\
Banks (x) & 0.463418 & 1.000000 & 0.335843 \\
NBFI (y) & 0.240646 & 0.335843 & 1.000000 \\
Insurance (z) & & & \\
\hline
\end{tabular}

TABLE III: PAIRWISE GRANGer CAUSALITy TESTS

\begin{tabular}{llll}
\hline \multirow{2}{*}{ Regressors } & \multicolumn{3}{c}{ Response variables } \\
\cline { 2 - 4 } & $\begin{array}{l}\text { Commercial } \\
\text { Banks (x) }\end{array}$ & NBFI (y) & Insurance (z) \\
\hline $\begin{array}{l}\text { Commercial } \\
\text { Banks (x) }\end{array}$ & $16.48 * * *$ & $426.397 * * *$ \\
NBFI (y) & 1.33 & & $426.397 * * *$ \\
Insurance (z) & $51.02 * * *$ & $13.60 * * *$ & \\
\hline
\end{tabular}

*** Implies significant at $1 \%$ level.

\begin{tabular}{ccc}
\multicolumn{3}{c}{ TABLE IV: UNIT ROOT TEST } \\
\hline Variables & ADF test & Phillips-Perron test \\
\hline Commercial Banks & $-36.64 * * *$ & $-36.62 * * *$ \\
(x) & & \\
NBFI (y) & $-35.79 * * *$ & $-35.81 * * *$ \\
Insurance (z) & $-21.70^{* * *}$ & $-33.48^{* * *}$ \\
\hline **** Implies signifion
\end{tabular}

*** Implies significance at $1 \%$ level.

\section{EMPIRICAL MODELS}

\section{A. Bayesian VAR Model}

In this paper, we have used Bayesian version of vector autoregression (VAR) to test return spillover among commercial banks, NBFIs, and insurance companies and we have also used VAR equations as conditional mean equation in GARCH models to test volatility spillover between these return series. Endogenous variables are considered up to two lags in the VAR based on Akaike Information Criteria. Vector autoregression is commonly used for analyzing dynamic impact of random innovations on a system of interrelated times series. The difference between Bayesian VAR (BVAR) and traditional VAR is that the model parameters are treated as random variables, and prior probabilities are assigned to them.

The parameter space of VARS proliferates with the number of dependent variables and the number of lags and according to Koop et al. [26], this over-parameterization problem can be solved by Bayesian shrinkage through restrictions on parameter set. In this paper we have used Minnesota prior (proposed by Litterman [27], [28] and subsequently developed by other researchers at University of Minnesota) to assign prior probabilities to random model parameter.

Conditional mean equations (Bayesian VAR model):

$$
\begin{aligned}
& X=\theta_{X}+\sum_{i=1}^{2} \omega_{i} X_{t-i}+\sum_{j=1}^{2} \delta_{j} Y_{t-j}+\sum_{k=1}^{2} \psi_{k} Z_{t-k}+\varepsilon_{X} \\
& Y=\theta_{Y}+\sum_{i=1}^{2} \omega_{i} Y_{t-i}+\sum_{j=1}^{2} \delta_{j} X_{t-j}+\sum_{k=1}^{2} \psi_{k} Z_{t-k}+\varepsilon_{Y} \\
& Z=\theta_{Z}+\sum_{i=1}^{2} \omega_{i} Z_{t-i}+\sum_{j=1}^{2} \delta_{j} X_{t-j}+\sum_{k=1}^{2} \psi_{k} Y_{t-k}+\varepsilon_{Z}
\end{aligned}
$$

Threshold GARCH or GJR-GARCH model: This model was developed independently by Glosten, Jagannathan, and Runkle [13] and Zakoïan [29]. In this model, we have used some variance regressors in the conditional variance equations to test the volatility spillover effect. In this model, a dummy variable (dt-1) is used to capture the differential impact of good news and bad news on volatility where, dt-1 = 1 if $\varepsilon \mathrm{t}-1<0$ and dt- $1=0$ otherwise. If the estimated value of $\gamma>0$ then we can conclude that the asymmetry effect or leverage effect is present and bad news $(\varepsilon t-1<0)$ or negative shocks increases volatility more than the good news ( $\varepsilon t-1>0)$. We have used maximum likelihood estimation method to estimate T-GARCH model and assumed that errors are normally distributed. Maximum likelihood estimation method involves in estimating the unknown parameters in such a manner that the probability of observing the endogenous variable is as high as possible (i.e. maximize the log likelihood-1lf). Estimated parameter values are no different in maximum likelihood estimation than in OLS except that the estimated conditional variance is biased downward in small samples but in asymptotically large sample this bias tends to be zero, i.e., the estimated value of conditional variances converges to its true value [30].

TABLE V: RETURN SPILLOVER TEST (BAYESIAN VAR OUTPUT)

\begin{tabular}{|c|c|c|c|c|}
\hline \multicolumn{2}{|c|}{ Regressors } & $\mathrm{X}$ & $\mathrm{Y}$ & $\mathrm{Z}$ \\
\hline$\theta$ & -0.0014 & -0.0011 & -0.0007 \\
\hline \multicolumn{2}{|c|}{$\omega_{1}$} & $0.0471 *$ & 0.0049 & $0.089 * * *$ \\
\hline$\omega_{2}$ & $-0.19 * * *$ & -0.026 & $0.0379 *$ \\
\hline \multirow{3}{*}{$\begin{array}{c}\text { Return } \\
\text { Spillover } \\
\text { Coefficients }\end{array}$} & $\delta_{1}$ & -0.0025 & $0.154 * * *$ & $0.45 * * *$ \\
\cline { 2 - 5 } & $\delta_{2}$ & -0.0432 & $-0.104 * * *$ & $-0.0347 *$ \\
\cline { 2 - 5 } & $\psi_{1}$ & $0.4867 * * *$ & $0.278 * * *$ & $0.0708 * * *$ \\
\cline { 2 - 5 } & $\psi_{2}$ & 0.0505 & $0.0472 *$ & -0.029 \\
\hline
\end{tabular}

$* * *, * *$ and $*$ imply significance at $1 \%, 5 \%$, and $10 \%$, respectively.

Exponential GARCH or E-GARCH model: This model is developed by Nelson [12] as an extension of the Bollerslev and Bollerslev et al.'s [31], [32] GARCH model. The bivariate version of E-GARCH used in this paper is 
developed by Braun et al. [18], Kroners and $\mathrm{Ng}$ [19], [33], Henry and Sharma [34] and Cho and Engle [35]. In E-GARCH model, we use natural $\log$ of the conditional variance as the dependent variable and hence leverage effect is exponential and forecast of the conditional variance is always positive and do not require parameter restrictions to impose non-negativity. If the estimated value of $\gamma \neq 0$, then we can conclude the presence of asymmetry effect in the model. This model has also been estimated using maximum likelihood estimation method assuming that errors are normally distributed.

Conditional variance equations (T-GARCH or GJR-GARCH model)

$$
\begin{aligned}
\sigma_{X_{t}}^{2}= & \eta_{X}+\alpha \varepsilon_{x_{t-1}}^{2}+\beta \sigma_{X_{t-1}}^{2}+\gamma \varepsilon_{X_{t-1}}^{2} d_{t-1} \\
& +\sum_{i=0}^{1} \xi_{i} \sigma_{Y_{t-i}}^{2}+\sum_{i=0}^{1} \varphi_{i} \varepsilon_{Y_{t-i}}^{2}+\sum_{j=1}^{2} \chi_{j} \sigma_{Z_{t-j}}^{2}+\sum_{j=0}^{1} \rho_{j} \varepsilon_{Z_{t-j}}^{2} \\
\sigma_{Y_{t}}^{2}= & \eta_{Y}+\alpha \varepsilon_{Y_{t-1}}^{2}+\beta \sigma_{Y_{t-1}}^{2}+\gamma \varepsilon_{Y_{t-1}}^{2} d_{t-1} \\
& +\xi \sigma_{X_{t}}^{2}+\varphi \varepsilon_{X_{t}}^{2}+\sum_{j=0}^{2} \chi_{j} \sigma_{Z_{t-j}}^{2}+\sum_{j=0}^{2} \rho_{j} \varepsilon_{Z_{t-j}}^{2} \\
\sigma_{Z_{t}}^{2}= & \eta_{Z}+\alpha \varepsilon_{Z_{t-1}}^{2}+\beta \sigma_{Z_{t-1}}^{2}+\gamma \varepsilon_{Z_{t-1}}^{2} d_{t-1} \\
& +\sum_{i=0}^{1} \xi_{i} \sigma_{X_{t-i}}^{2}+\sum_{i=0}^{2} \varphi_{i} \varepsilon_{X_{t-i}}^{2}+\sum_{j=0}^{1} \chi_{j} \sigma_{Y_{t-j}}^{2}+\sum_{j=0}^{2} \rho_{j} \varepsilon_{Y_{t-j}}^{2}
\end{aligned}
$$

Conditional variance equations (E-GARCH model)

$$
\begin{gathered}
\log \left(\sigma_{X_{t}}^{2}\right)=\eta_{X}+\alpha\left|\frac{\varepsilon_{X_{t-1}}}{\sigma_{X_{t-1}}}\right|+\beta \log \left(\sigma_{X_{t-1}}^{2}\right)+\gamma \frac{\varepsilon_{X_{t-1}}}{\sigma_{X_{t-1}}} \\
+\xi \log \left(\sigma_{Y_{t}}^{2}\right)+\sum_{i=0}^{1} \varphi_{i} \varepsilon_{Y_{t-i}}^{2}+\sum_{j=0}^{2} \chi_{j} \log \left(\sigma_{Z_{t-j}}^{2}\right)+\sum_{j=0}^{2} \rho_{j} \varepsilon_{Z_{t-j}}^{2} \\
\log \left(\sigma_{Y_{t}}^{2}\right)=\eta_{Y}+\alpha\left|\frac{\varepsilon_{Y_{t-1}}}{\sigma_{Y_{t-1}}}\right|+\beta \log \left(\sigma_{Y_{t-1}}^{2}\right)+\gamma \frac{\varepsilon_{Y_{t-1}}}{\sigma_{Y_{t-1}}} \\
+\sum_{i=0}^{1} \xi_{i} \log \left(\sigma_{X_{t-i}}^{2}\right)+\sum_{i=0}^{2} \varphi_{i} \varepsilon_{X_{t-i}}^{2}+\sum_{j=0}^{2} \chi_{j} \log \left(\sigma_{Z_{t-j}}^{2}\right)+\sum_{j=0}^{2} \rho_{j} \varepsilon_{Z_{t-j}}^{2} \\
\log \left(\sigma_{Z_{t}}^{2}\right)=\eta_{Z}+\alpha\left|\frac{\varepsilon_{Z_{t-1}}}{\sigma_{Z_{t-1}}}\right|+\beta \log \left(\sigma_{Z_{t-1}}^{2}\right)+\gamma \frac{\varepsilon_{Z_{t-1}}}{\sigma_{Z_{t-1}}} \\
+\xi \log \left(\sigma_{X_{t}}^{2}\right)+\varphi \varepsilon_{X_{t}}^{2}+\chi \log \left(\sigma_{Y_{t-1}}^{2}\right)+\sum_{j=0}^{2} \rho_{j} \varepsilon_{Y_{t-j}}^{2}
\end{gathered}
$$

\section{FINDINGS}

\section{A. Return Spillover Analysis}

We have used Bayesian VAR to test return spillover effects between commercial banks, NBFIs and insurance companies traded in Dhaka Stock Exchange (DSE) from January, 2009 to January, 2016. From Table V, we can see a highly significant memory effect on commercial banks and insurance companies indicating that commercial bank returns and return from insurance companies are influenced by their own previous performances. NBFIs seem to have no spillover effect on commercial banks consistent with our Granger causality output, but commercial bank returns have highly significant effect on NBFI returns. Highly significant bi-directional return spillover effect has been observed for both bank-insurance pair and insurance-NBFI pair, where yesterday's return has higher spillover effect compared to return form day before yesterday.

\section{B. Volatility Spillover Analysis (GJR-GARCH output)}

A highly significant ARCH effect is visible on conditional variance of commercial bank and NBFI series from GJR-GARCH output of Table VI. This indicates that news about volatility from previous period innovations or shocks have contributed significantly in predicting next period conditional variance. Last period forecast variance or historical volatility also has highly significant effect on conditional variance of all return series. Gamma coefficient indicates a highly significant asymmetric news impact on conditional variance of NBFI return series indicating good news $(\varepsilon t-1>0)$ and bad news $(\varepsilon t-1<0)$ have differential effect on it. The sum of ARCH and GARCH coefficients $(\alpha+\beta)$ is very close to one, indicating that volatility shocks are quite

\begin{tabular}{|c|c|c|c|c|}
\hline Regressors & & $\sigma_{X_{t}}^{2}$ & $\sigma_{Y_{t}}^{2}$ & $\sigma_{Z_{t}}^{2}$ \\
\hline$\eta$ & & $.58 \mathrm{E}-06^{* * *}$ & $0.0008 * * *$ & $-1.04 \mathrm{E}-06$ \\
\hline$\alpha$ & & $0.197 * * *$ & $0.617 * * *$ & $0.113^{*}$ \\
\hline \multicolumn{2}{|l|}{$\beta$} & $0.726 * * *$ & $0.404 * * *$ & $0.367 * * *$ \\
\hline \multicolumn{2}{|l|}{$\gamma$} & 0.024 & $-0.564 * * *$ & 0.052 \\
\hline \multirow{11}{*}{$\begin{array}{c}\text { Volatility } \\
\text { Spillover } \\
\text { Coefficients }\end{array}$} & $\xi$ & $0.577 * * *$ & $-0.0097 * * *$ & $0.069 * * *$ \\
\hline & $\xi_{1}$ & -0.0003 & & $-0.048 * * *$ \\
\hline & $\varphi$ & $2.02 \mathrm{E}-05$ & -0.002 & -0.0002 \\
\hline & $\varphi_{1}$ & $1.54 \mathrm{E}-05$ & & $0.003 * * *$ \\
\hline & $\varphi_{2}$ & & & $-0.002 * * *$ \\
\hline & $\chi$ & & $0.176^{*}$ & $0.428 * * *$ \\
\hline & $\chi_{1}$ & $-0.826 * * *$ & 0.055 & $0.009 * *$ \\
\hline & $\chi_{2}$ & $0.356 * * *$ & -0.031 & \\
\hline & $\rho$ & -0.0004 & 0.0003 & 0.0001 \\
\hline & $\rho_{1}$ & $0.0005^{* *}$ & $-0.009 * * *$ & $-0.0005 * * *$ \\
\hline & $\rho_{2}$ & & $-0.024 * * *$ & $1.26 \mathrm{E}-05$ \\
\hline \multicolumn{2}{|l|}{ Log likelihood } & 4528.840 & 3363.749 & 4470.363 \\
\hline \multicolumn{2}{|c|}{ Akaike Info Criterion } & -5.356 & -3.971 & -5.280 \\
\hline \multicolumn{2}{|c|}{${ }^{2} \mathrm{LB}-\mathrm{Q}(12)$} & 4.889 & 0.019 & 3.288 \\
\hline
\end{tabular}
persistent or die out very slowly for both commercial bank and NBFI series. Correlogram (autocorrelations and partial autocorrelations) of the squared standardized residual test is used for residual diagnostic to check the specification and identify presence of any remaining $\mathrm{ARCH}$ in the variance equation and from Table VI we can see that Ljung-Box Q-stat at lag 12 is not significant for all variance equations and thereby indicating that the variance equations we used successfully modelled all available ARCH effects in return series under study.

TABLE VI: CONDITIONAL VARIANCE EQUATION: GJR-GARCH

$* * *, * *$ and $*$ imply significance at $1 \%, 5 \%$, and $10 \%$, respectively.

${ }^{2}$ Ljung-Box Q-stat from correlogram of squared standardized residual test output at lag 12 .

Bi-directional volatility spillover in the form of forecasted conditional variance is clear between both bank-NBFI and bank-insurance pair where shock is transmitting both way from NBFIs to bank and bank to NBFIs through latest forecast variance. Volatility transmission from bank to insurance is through latest and last period forecast variance where for insurance to bank, transmission is taking place through lag 1 and lag 2 of conditional variance. Financial 
shock transmission in the form of forecasted conditional variance between NBFIs and insurance companies is unidirectional, only latest and last period forecast variance of NBFIs is transmitted to insurance companies.

News about volatility irrespective of good news or bad news creates volatility in stocks and this shock in one stock can be transmitted to other stocks in the same industry and eventually can even be transferred to all stocks in local and international markets The $\varphi$ and $\rho$ coefficients at Table VI indicate volatility spillover in the form of news impact or squared innovations. A bi-directional volatility spillover in the form of squared disturbances is evident between bank-insurance and NBFI-insurance pair where news about volatility as lag 1 and lag 2 of squared disturbances is transmitting from bank to insurance and only last period squared innovation of insurance series has statistically significant effect on bank. Financial shocks originated from NBFIs in the form of last period news impact or lag 1 squared residuals have statistically significant effect on conditional variance of insurance companies where both lag 1 and lag 2 squared residuals from insurance series is influencing conditional variance forecast of NBFIs. No statistically significant volatility spillover in the form of news about volatility is observed between bank-NBFIs pair.

TABLE VII: CONDITIONAL VARIANCE EQUATION: E-GARCH

\begin{tabular}{|c|c|c|c|c|}
\hline \multicolumn{2}{|c|}{ Regressors } & $\log \sigma_{X_{t}}^{2}$ & $\log \sigma_{Y_{t}}^{2}$ & $\log \sigma_{Z_{t}}^{2}$ \\
\hline \multicolumn{2}{|l|}{$\eta$} & $-0.37 * * *$ & $-4.143 * * *$ & -0.835 \\
\hline \multicolumn{2}{|l|}{$\alpha$} & $0.25 * * *$ & $0.991 * * *$ & $0.361 * * *$ \\
\hline \multicolumn{2}{|l|}{$\beta$} & $0.97 * * *$ & $0.562 * * *$ & $0.928 * * *$ \\
\hline \multicolumn{2}{|l|}{$\gamma$} & $-0.03 * * *$ & $0.710 * * *$ & $-0.027^{*}$ \\
\hline \multirow{11}{*}{$\begin{array}{c}\text { Volatility } \\
\text { Spillover } \\
\text { Coefficients }\end{array}$} & $\xi$ & -0.003 & $-0.379 * * *$ & $-0.056^{* * *} *$ \\
\hline & $\xi_{1}$ & & 0.050 & \\
\hline & $\varphi$ & $1.29 * *$ & $-2.761 * * *$ & $-2.480 * * *$ \\
\hline & $\varphi_{1}$ & $-1.99 * * *$ & $-10.047 * * *$ & \\
\hline & $\varphi_{2}$ & & 0.847 & \\
\hline & $\chi$ & $767.62 * * *$ & $203.647 * * *$ & $-0.008 * *$ \\
\hline & $\chi_{1}$ & $-1120.55^{* * *}$ & 101.454 & \\
\hline & $\chi_{2}$ & $352.99 * * *$ & -98.505 & \\
\hline & $\rho$ & $-2.15 * * *$ & $5.848 * * *$ & $1.658 * *$ \\
\hline & $\rho_{1}$ & $3.83 * *$ & $-6.187 * * *$ & $-3.542 * * *$ \\
\hline & $\rho_{2}$ & $-3.52 * *$ & $-12.018 * * *$ & 1.112 \\
\hline \multicolumn{2}{|l|}{ Log likelihood } & 4535.35 & 3993.661 & 4435.811 \\
\hline \multicolumn{2}{|c|}{$\begin{array}{l}\text { Akaike Info Criterion } \\
\text { (AIC) }\end{array}$} & -5.35 & -4.717 & -5.240 \\
\hline \multicolumn{2}{|l|}{${ }^{3} \mathrm{LB}-\mathrm{Q}(12)$} & 14.231 & 0.7460 & 1.9392 \\
\hline
\end{tabular}

$* * *, * *$ and $*$ imply significance at $1 \%, 5 \%$, and $10 \%$, respectively.

${ }^{3}$ Ljung-Box Q-stat from correlogram of squared standardized residual test output at lag 12 .

\section{Volatility Spillover Analysis (EGARCH output)}

EGARCH output from Table VII indicates that news about volatility from previous period shocks in the form of ARCH $(\alpha)$ have highly significant effect on next period conditional variance forecast of all series under consideration. Last period forecast variance or historical volatility $(\beta)$ also has highly significant effect on conditional variance of all return series. A highly significant asymmetric news impact on conditional variance of bank and NBFI return series is clearly evident from $\gamma$ coefficient and this coefficient is positive for NBFIs which indicates that bad news $\left(\varepsilon_{\mathrm{t}-1}<0\right)$ increases volatility of NBFIs more than good news. The sum of ARCH and GARCH coefficients $(\alpha+\beta)$ is more than one, indicating that volatility shocks are quite persistent or die out very slowly for all return series. Ljung-Box Q-stat of squared standardized residual at lag 12 indicates that the variance equations we used successfully modelled all available ARCH effects in all return series under study.

Volatility spillover in the form of news impact or squared innovations is indicated by $\varphi$ and $\rho$ coefficients in Table VII. A bi-directional volatility spillover, in the form of news about volatility in one stock transmitting to other stock, is clearly evident between bank-insurance, bank-NBFI and NBFI-insurance pair. Current and previous period shocks due to squared innovations are transmitting both ways from bank to NBFI and NBFI to bank. Only fresh news about volatility has highly significant effect on conditional variance of insurance series but fresh along with lag 1 and lag 2 squared innovations have highly statistically significant effect on conditional variance series of commercial bank series. Somewhat similar result has been observed for NBFI-insurance pair where both fresh and previous period news about volatility are transmitted from NBFI to insurance and volatility from fresh news and lag 1 and lag 2 squared innovations has been transmitted from insurance to NBFI series.
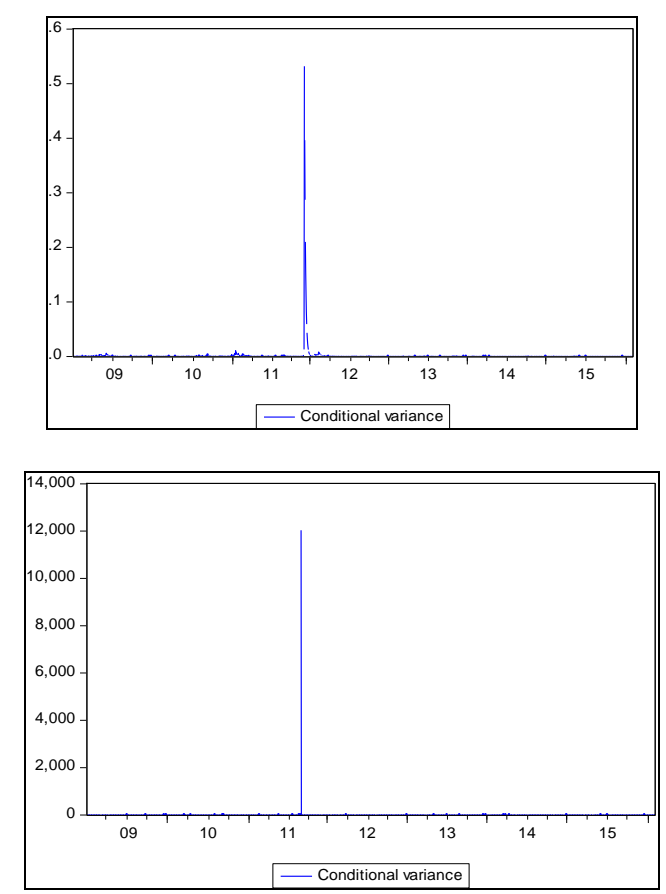

Fig. 3. Conditional variance of commercial bank series from EGARCH and TGARC H model.

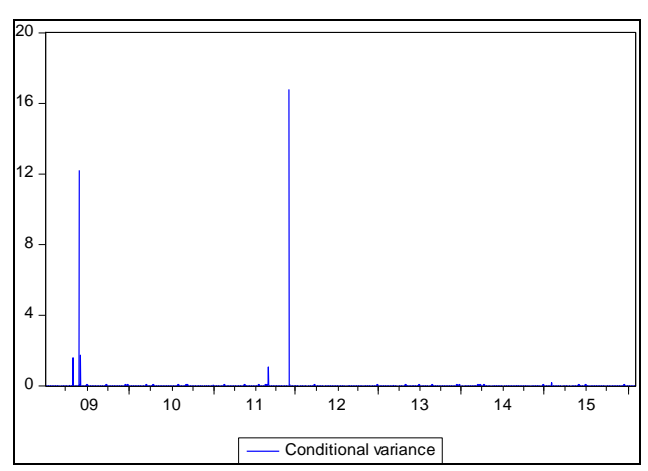




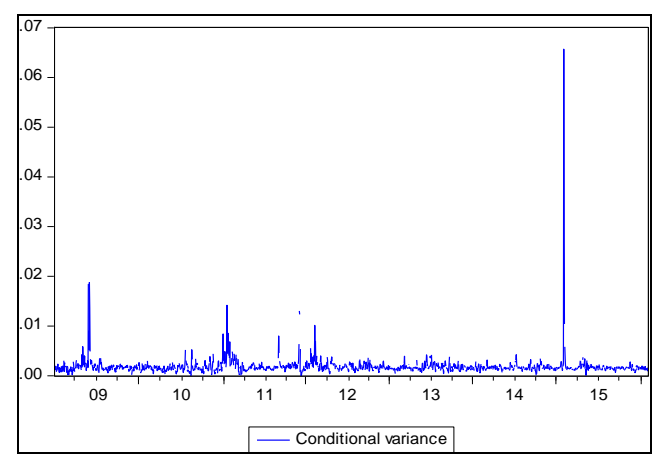

Fig. 4. Conditional variance of NBFI series from EGARCH and TGARCH model.
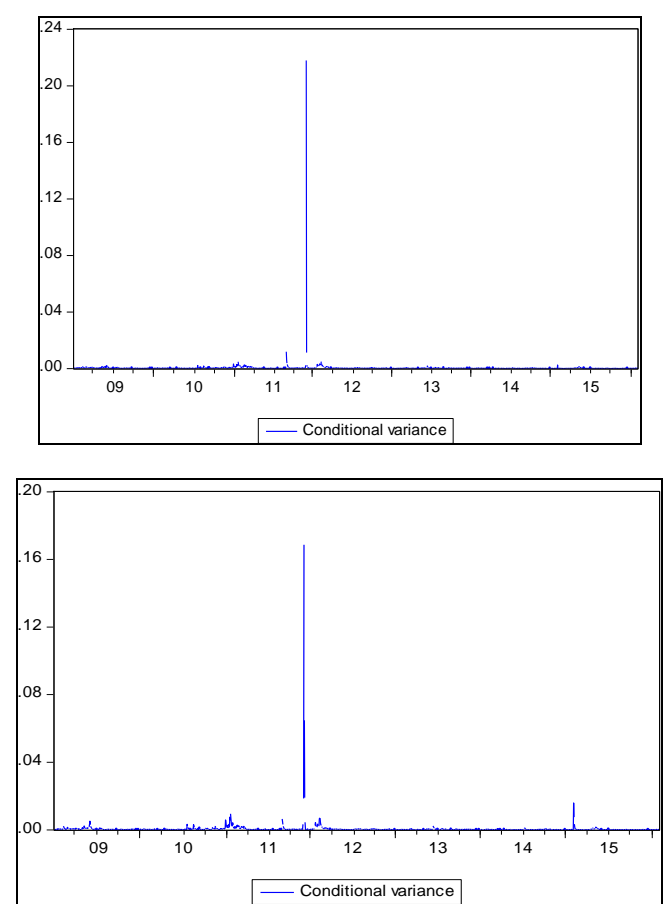

Fig. 5. Conditional variance of insurance series from EGARCH and TGARCH model.

Only one way volatility spillover in the form of latest forecast variance has been observed from bank to NBFIs and the transmission is bi-directional between both bank-insurance and NBFI-insurance pair. Fresh, lag 1 and lag 2 variance of insurance series have statistically significant effect on conditional variance of bank series where only fresh conditional variance forecast for bank series have significant spillover effect on insurance series. Only fresh conditional variance forecast for NBFI and insurance series have spillover effect on each other. Figs. 3 and 5 indicate that both EGARCH and TGARCH models smooth out volatility except for the abnormal volatility seen in the case of banks and insurance series at the end of 2011. Fig. 4 indicates quite a bit of random fluctuations in the NBFI series and both EGARCH and TGARCH models smooth out volatility except for some unusual volatility around 2009 and 2011.

\section{CONCLUSION}

In summary, we have used Bayesian VAR, E-GARCH and GJR-GARCH model to analyze daily returns to examine transmission of volatility in the broad financial sector of the Dhaka Stock Exchange stocks and the results are fairly consistent. We obtained continuously compounded daily returns and had taken the first differences generating stationary series. Bayesian VAR provided strong indication of bidirectional comovement of bank and insurance returns and returns being influenced by contiguous previous performance. Similar relationship was observed between insurance company returns and non-bank financial institution (NBFI) returns. Evidence indicates that bank return volatility spillover influences the NBFI returns, but the reverse is not true.

The GJR-GARCH model, when applied to bank returns and NBFI returns, indicates that volatility forecast from the period preceding periods as well as historical volatility significantly affect the conditional variance in the next period. In addition, the results indicate strong asymmetric news impact on conditional variance of NBFI returns. Clearly, good news effects are significantly different from bad news effects. Data also provide evidence of persistent effect of volatility shocks.

Volatility spillover between bank and NBFI and bank and insurance apparently take the form of forecasted conditional variance. Shock is transmitted bi-directionally through latest forecast variance. In the case of bank versus insurance, volatility transmission takes place through latest and last period forecast variance. In the case of bank versus insurance, however, the transmission medium is lag 1 and lag 2 of conditional variance. There was no evidence of volatility spillover between bank-NBFI pair originating from news. E-GARCH results were very similar and basically confirms the results of GJR-GARCH model.

We plan to extend our studies to examine linkage with the world market and also within other sectors of the economy. We know very little about the fundamental structure of the financial markets in Bangladesh and we believe that this work will encourage further work in this area.

APPENDIX

SECTOR: COMMERCIAL BANKS

\begin{tabular}{|l|l|l|l|l|}
\hline AB Bank & Mutual Trust Bank & Jamuna Bank & One Bank & Social IBL \\
\hline DBBL & Mercantile Bank & Bank Asia & Prime Bank & Southeast Bank \\
\hline Brac Bank & First Security Bank & Eastern Bank & Pubali Bank & Standard Bank \\
\hline Dhaka Bank & ICB Islami Bank & National Bank & Rupali Bank & City Bank \\
\hline EXIM Bank & Shahjalal Islami Bank & NCC Bank & IFIC Bank & Premier Bank \\
\hline
\end{tabular}

SECTOR: INSURANCE COMPANIES

\begin{tabular}{|l|l|l|l|l|}
\hline Prime Islami Life Ins. & Continental Ins. & Global Ins. & Northern Ins. & Popular Ins. \\
\hline Fareast Islami Ins. & Asia Pacific Ins. & Karnaphuly Ins. & City Ins. & Pragati Ins. \\
\hline Bangladesh General Ins. & Eastland Ins. & Central Ins. & Peoples Ins. & Prime Ins. \\
\hline Sandhani Life Ins. & Green Delta Ins. & Paramount Ins. & Phoenix Ins. & Eastern Ins. \\
\hline National Life Ins. & Mercantile Ins. & Agrani Ins. & Pioneer Ins. & Purabi Ins. \\
\hline Standard Ins. & Federal Ins. & Rupali Ins. & & \\
\hline
\end{tabular}


SECTOR: NON-BANK FINANCIAL INSTITUTIONS (NBFIS)

\begin{tabular}{|l|l|}
\hline Bangladesh Finance and Investment Company Ltd. (BFICL) & IDLC \\
\hline Bangladesh Industrial Finance Company Ltd. (BIFC) & IPDC \\
\hline Delta Brac Housing Finance Corporation Ltd. (DBHFCL) & ICB \\
\hline National Housing Finance and Investment & International Leasing \\
\hline Phoenix Finance and Investment & Islamic Finance \\
\hline Prime Finance and Investment & Lanka Bangla Finance \\
\hline Premier Leasing & Peoples Leasing \\
\hline Union Capital & Uttara Finance \\
\hline
\end{tabular}

\section{ACKNOWLEDGEMENT}

The authors would like to express their gratitude to Dr. Abdul Hannan Chowdhury for helpful comments and suggestions.

\section{REFERENCES}

[1] W. Sharpe, "Capital asset prices: A theory of market equilibrium under conditions of risk," Journal of Finance, vol. 19, no. 3, pp. 425-42, September 1964

[2] J. Lintner, "Security prices, risk and maximum gains from diversification," Journal of Finance, vol. 20, no. 4, pp. 587-615, December 1965.

[3] M. A. Rayhan, S. M. A., Sarker, and S. M. Sayem, "The volatility of Dhaka Stock Exchange (DSE) returns: Evidence and implications," ASA University Review, vol. 5, no. 2, pp. 87-99, July 2011.

[4] M. Z. Alam, M. N. Siddikee and M. Masukujjaman, "Forecasting volatility of stock indices with ARCH model," International Journal of Financial Research, vol. 4, no. 2, pp. 126-143, April 2013.

[5] M. S. I. Aziz and M. N. Uddin, "Volatility estimation in the Dhaka Stock Exchange (DSE) returns by GARCH models," Asian Business Review, vol. 4, no. 1, pp. 41-49, February 2014.

[6] A. T. Mollik and M. K. Bepari, "Feedback trading behavior in Dhaka Stock Exchange (DSE), Bangladesh," International Review of Business Research Papers, vol. 9, no. 5, pp. 154-168, September 2013.

[7] M. Miah and A. Rahman, "Modelling volatility of daily stock returns: is GARCH $(1,1)$ enough," American Scientific Research Journal for Engineering, Technology, and Sciences (ASRJETS), vol. 18, no. 1, pp. 29-39, March 2016.

[8] S. A. Basher, M. K. Hassan, and A. M. Islam, "Time-varying volatility and equity returns in Bangladesh stock market," Applied Financial Economics, vol. 17, pp. 1393-1407, November 2007.

[9] M. M. Rahman, J. P. Zhu, and M. S. Rahman, "Impact study of volatility modelling of Bangladesh stock index using non-normal density," Journal of Applied Statistics, vol. 35, no. 11, pp. 1277-129, November 2008.

[10] H. Gatfaoui, "Translating financial integration into correlation risk: A weekly reporting's viewpoint for the volatility behavior of stock markets," Economic Modelling, vol. 30, no. 1, pp. 776-791, January 2012.

[11] C. Brooks, Introductory Econometrics for Finance, 2nd ed., Cambridge Univ. Press, 2008.

[12] D. B. Nelson, "Conditional Heteroscedasticity in Asset Returns: A New Approach," Econometrica, vol. 59, pp. 347-370, March 1991.

[13] L. R. Glosten, R. Jagannathan, and D. E. Runkle, "On the relation between the expected value and the global volatility of the nominal excess return on stocks," The Journal of Finance, vol. 48, no. 5, pp. 1779-1801, December 1993.

[14] H. Liu and J. Hung, "Forecasting S\&P-100 stock index volatility: The role of volatility asymmetry and distributional assumption in GARCH models," Expert Systems with Applications, vol. 37, pp. 4928-4934, July 2010.

[15] K. N. Mukherjee and R. K. Mishra, "Stock market integration and volatility spill-over: India and its major Asian counterparts," Research in International Business and Finance, vol. 24, no. 2, pp. 235-251, June 2010.

[16] A. Kanas, "Volatility spill-overs across equity markets: European evidence," Applied Financial Economics, vol. 8, pp. 245-256, June 1998.

[17] G. Koutmos and G. Booth, "Asymmetric volatility transmission in international stock markets," Journal of International Money and Finance, vol. 14, pp. 747-762, December 1995.

[18] P. A. Braun, D. B. Nelson, and A. M. Sunier, "Good news, bad news, volatility and betas," Journal of Finance, vol. 50, pp. 1575-1603, December 1995
[19] K. F. Kroner, and V. K. Ng, "Multivariate GARCH modelling of asset returns," Papers and Proceedings of the American Statistical Association, Business and Economics Section, pp. 31-46, 1996.

[20] R. Bhar and B. Nikolova, "Oil prices and equity returns in the BRIC countries," The World Economy, vol. 32, no. 7, pp. 1036-1054, July 2009.

[21] K. Iwatsubo and K. Inagaki, (2007). "Measuring financial market contagion using dually-traded stocks of Asian firms," Journal of Asian Economics, vol. 18, pp. 217-236, February 2007.

[22] L. Morales and E. Gassie, "Structural breaks and financial volatility: Lessons from BRIC countries," Unpublished, 2011.

[23] J. Yang, C. Hsiao, Q. Li, and Z. Z. Wang, "The emerging market crisis and stock market linkages: Further evidence," Journal of Applied Econometrics, vol. 21, pp. 727-744, Month 2006 .

[24] D. A. Dickey and W. A. Fuller, "Distribution of the estimators for autoregressive time series with a unit root," Journal of the American Statistical Association, vol. 74, pp. 427-431, June 1979.

[25] D. A. Dickey and W. A. Fuller, "Likelihood ratio statistics for autoregressive time series with a unit root," Econometrica, vol. 49, no. 4, pp. 1057-1072, July 1981.

[26] G. Koop, D. J. Poirier, and J. L. Tobias, Bayesian Econometric Methods, Cambridge Univ. Press, 2007.

[27] R. Litterman, "Techniques of forecasting using vector autoregressions," Federal Reserve Bank of Minneapolis Working Paper, p.115, 1979.

[28] R. Litterman, "A Bayesian procedure for forecasting with vector autoregression," Working Paper, Massachusetts Institute of Technology, Department of Economics, 1980.

[29] J. M. Zakoïan, "Threshold Heteroskedastic Model," Unpublished Manuscript (INSEE, Paris), 1994.

[30] D. N. Gujarati, Basic Econometrics, 4th ed., McGraw-Hill, New York, 2003.

[31] T. Bollerslev, "Generalized autoregressive conditional heteroscedasticity," Journal of Econometrics, vol. 31, pp. 307-327, April 1986.

[32] T. Bollerslev, R. Y. Chou, and K. F. Kroner, "ARCH modelling in finance," Journal of Econometrics, vol. 52, pp. 5-59, April 1992.

[33] K. F. Kroner and V. K. Ng, "Modelling asymmetric comovements of asset returns," Review of Financial Studies, vol. 11, pp. 44-817, October 1998

[34] O. T. Henry and J. S. Sharma, "Asymmetric conditional volatility and firm size: Evidence from Australian equity portfolios" Australian Economic Papers, vol. 38, pp. 393-407, December 1999.

[35] Y. H. Cho and R. F. Engle, "Time varying betas and asymmetric effects of news: empirical analysis of blue chip stocks," NBER Working Paper, p. 7330, September 1999.

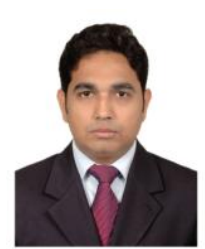

Mohammad K. Arefin is a senior lecturer at the Faculty of Business Administration at Eastern University Dhaka. His research interest principally centers around studying market volatility and investment behavior. He earned a master of science in quantitative finance from the University of Glasgow.

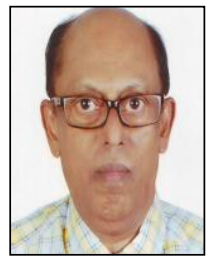

Sharif N. Ahkam is a professor of Finance at North South University, Dhaka, Bangladesh. He holds a D. B. A. from Kent State University, USA. His primary research interests center around corporate finance, international financial markets, small capital markets, mutual funds, and working capital management. He has published numerous articles in reputed business journals. 